\title{
Comparative and phylogenetic analyses of eleven complete chloroplast genomes of Dipterocarpoideae
}

Yang Yu ${ }^{1 \dagger}$, Yuwei Han ${ }^{1 \dagger}$, Yingmei Peng ${ }^{1 \dagger}$, Zunzhe Tian ${ }^{1}$, Peng Zeng ${ }^{2}$, Hang Zong ${ }^{1}$, Tinggan Zhou ${ }^{1}$ and Jing $\mathrm{Cai}^{1 *}$ (D)

\begin{abstract}
Background: In South-east Asia, Dipterocarpoideae is predominant in most mature forest communities, comprising around $20 \%$ of all trees. As large quantity and high quality wood are produced in many species, Dipterocarpoideae plants are the most important and valuable source in the timber market. The $d$-borneol is one of the essential oil components from Dipterocarpoideae (for example, Dryobalanops aromatica or Dipterocarpus turbinatus) and it is also an important traditional Chinese medicine (TCM) formulation known as "Bingpian" in Chinese, with antibacterial, analgesic and anti-inflammatory effects and can enhance anticancer efficiency.
\end{abstract}

Methods: In this study, we analyzed 20 chloroplast (cp) genomes characteristics of Dipterocarpoideae, including eleven newly reported genomes and nine cp genomes previously published elsewhere, then we explored the chloroplast genomic features, inverted repeats contraction and expansion, codon usage, amino acid frequency, the repeat sequences and selective pressure analyses. At last, we constructed phylogenetic relationships of Dipterocarpoideae and found the potential barcoding loci.

Results: The cp genome of this subfamily has a typical quadripartite structure and maintains a high degree of consistency among species. There were slightly more tandem repeats in cp genomes of Dipterocarpus and Vatica, and the $\mathrm{psbH}$ gene was subjected to positive selection in the common ancestor of all the 20 species of Dipterocarpoideae compared with three outgroups. Phylogenetic tree showed that genus Shorea was not a monophyletic group, some Shorea species and genus Parashorea are placed in one clade. In addition, the rpoC2 gene can be used as a potential marker to achieve accurate and rapid species identification in subfamily Dipterocarpoideae.

Conclusions: Dipterocarpoideae had similar $\mathrm{cp}$ genomic features and $p s b M, r b c L, p s b H$ may function in the growth of Dipterocarpoideae. Phylogenetic analysis suggested new taxon treatment is needed for this subfamily indentification. In addition, rpoC2 is potential to be a barcoding gene to TCM distinguish.

Keywords: Dipterocarpoideae, Chloroplast genomes, Comparative genomics, Selected selection, Phylogenetics, DNA barcoding

\footnotetext{
*Correspondence: jingcai@nwpu.edu.cn

${ }^{\dagger}$ Yang Yu, Yuwei Han and Yingmei Peng contributed equally to this work

${ }^{1}$ School of Ecology and Environment, Northwestern Polytechnical University, Xi'an, China

Full list of author information is available at the end of the article
}

\section{Background}

Dipterocarpaceae is a small eudicot family with many giant plants, it is the symbol of South-east Asian tropical rain forests and many seasonally dry forests [1]. This family includes two subfamilies, Monotoideae and Dipterocarpoideae. Dipterocarpoideae is the larger one with original author(s) and the source, provide a link to the Creative Commons licence, and indicate if changes were made. The images or other third party material in this article are included in the article's Creative Commons licence, unless indicated otherwise in a credit line to the material. If material is not included in the article's Creative Commons licence and your intended use is not permitted by statutory regulation or exceeds the permitted use, you will need to obtain permission directly from the copyright holder. To view a copy of this licence, visit http://creativecommons.org/licenses/by/4.0/. The Creative Commons Public Domain Dedication waiver (http://creativeco mmons.org/publicdomain/zero/1.0/) applies to the data made available in this article, unless otherwise stated in a credit line to the data. 
470-650 species in 13 genera [2, 3]. In South-east Asia, the dominance of Dipterocarpoideae is evident in most mature forest communities, comprising around $20 \%$ of all trees $[4,5]$. Many members of this subfamily are typically 40-70 m tall, with some plants reaching as high as $85 \mathrm{~m}$ [6]. As large quantity and high quality wood are produced in many species of Dipterocarpoideae, they are the most important and valuable source in the timber market [7, 8]. The $d$-borneol is one of the essential oil components from Dipterocarpoideae (for example, Dryobalanops aromatica or Dipterocarpus turbinatus) $[9,10]$. Borneol is also an important traditional Chinese medicine (TCM) formulation known as "Bingpian" in Chinese, with antibacterial [11], analgesic and anti-inflammatory effects [12] and can enhance anticancer efficiency [13]. Thus, borneol has been widely used in the fields of medicine, pesticide and chemical industry [14]. This TCM has been recorded in Newly Revised Canon of Materia Medica (Xinxiu Bencao) for more than 1300 years. Due to the medicinal and economic values of Dipterocarpoideae, the species have been the targets of woodcutting for long history. Some species such as Parashorea chinensis and $D$. aromatica even become endangered because of the over-harvesting $[15,16]$. Although Dipterocapoideae is important to forest ecology, conservation and medicine, little is known about the genetics of those species. The classifications of Dipterocarpoideae have been reported before, while delineation of genus Parashorea and Shorea still remains controversial, due to the difficulty in identifying these plants leads to an uneven quality of borneol medicinal materials. Chloroplast (cp) genome information will prove essential to solve this problem. Recently, the whole cp genomes of nine species in Dipterocarpoideae were sequenced and analyzed $[17,18]$. Here we sequenced, assembled and annotated the cp genomes of eleven species in four genera with the highest species richness in Dipterocarpoideae (Hopea mollissima, Hopea odorata, Shorea henryana, Shorea roxburghii, Shorea leprosula, Dipterocarpus gracilis, Dipterocarpus alatus, Dipterocarpus intricatus, Vatica xishuangbannaensis, Vatica odorata, Vatica rassak). Further, we performed a comprehensive evolutionary analysis of the cp genomes of 20 species from Dipterocapoideae and identified barcoding loci that could be used for species identification.

\section{Materials and methods}

\section{Sample collection, DNA extraction, and sequencing}

The fresh and healthy leaves of eleven species (Hopea mollissima, Hopea odorata, Shorea henryana, Shorea roxburghii, Shorea leprosula, Dipterocarpus gracilis, Dipterocarpus alatus, Dipterocarpus intricatus, Vatica xishuangbannaensis, Vatica odorata, Vatica rassak) were collected from the Xishuangbanna Tropical
Botanical Garden, Chinese Academy of Sciences, $\left(101^{\circ} 25^{\prime} \mathrm{E}, 21^{\circ} 41^{\prime} \mathrm{N}\right)$ and were immediately quickfrozen in liquid nitrogen. The total genomic DNA was extracted from leaf tissues with a modified Cetyl Trimethyl Ammonium Bromide (CTAB) method [19]. All genome DNA were sequenced with an Illumina NovaSeq 6000 platform by Biomarker Technologies, Inc (Beijing, China). The clean reads were more than $5,000 \times$ coverage of each whole cp genome.

\section{Genome assembly and annotations}

We used Getorganelle v1.7.1 [20] and NOVOPlasty $\mathrm{v} 4.2[21]$ to assemble chloroplast genome respectively, and selected the more complete result as the final genome. Five cp genomes were assembled using Getorganelle v1.7.1 (H. mollissima, D. gracilis, D. alatus, D. intricatus, $V$. odorata) and other six species cp genome using NOVOPlasty v4.2 (H. odorata, $S$. henryana, S. roxburghii, S. leprosula, $V$. xishuangbannaensis, $V$. rassak). The contigs were examined based on the complete chloroplast sequence of $D$. turbinatus (GenBank Accession Number: NC_046842) using the "Map to Reference" function of Genious Prime 2021.0.3 (https://www.geneious.com). We modified the relative position and direction of each contig. Then, the reads were applied to polish the assembled contigs using Nextpolish [22] to fill the gap. The newly assembled chloroplast genomes were annotated using Plastid Genome Annotator (PGA) software [23] with the cp genome of $D$. turbinatus as reference, whereas the tRNA genes were further verified by ARAGORN v1.2.38 [24] and tRNAscan-SE v2.0.7 [25], and then checked manually. Fully annotated plastomes of circular diagram were drawn by OrganellarGenomeDRAW (OGDRAW) [26].

Repeat sequences were detected using Tandem Repeats Finder (TRF) version 4.09 [27] and RepeatMasker version 1.317 (http://www.repeatmasker.org) with default parameters. The Perl script auto_repeat. pl from Zhouheling (zhouheling@genomics.org.cn) was used to analyze four types of Transposable Elements -DNA transposons, LINE (long interspersed nuclear elements), SINE (short interspersed nuclear elements) and LTR (long terminal repeats) in the chloroplast genomes of Dipterocarpoideae species.

\section{Comparative analyses}

To investigate the divergence in the chloroplast genome, the identity across the whole complete $\mathrm{cp}$ genomes were visualized using the shuffle-LAGAN program of mVISTA v2.0 program [28] for the 23 species, with the $H$. mollissima genome as the reference. To detect the variation in the LSC/IR/SSC boundaries 
of Dipterocarpoideae chloroplast genomes, all 20 chloroplast genomes of Dipterocarpoideae species were compared by drawing in Adobe Illustrator CC2019 (https://adobe.com/products/illustrator). Codon usage in these genes was assessed using the program codonW [29]. Six values were used to estimate the extent of bias toward codons: the codon adaptation index (CAI), codon bias index (CBI), frequency of optimal codons (Fop), the effective number of codons (ENc), GC content of synonymous third codons positions (GC3s) and the relative synonymous codon usage values (RSCU).

Species pairwise $K_{a} / K_{s}$ ratios and positive selection analysis Pairwise $\mathrm{K}_{\mathrm{a}} / \mathrm{K}_{\mathrm{s}}$ ratios of all species were calculated using the concatenated 50 single-copy genes alignments with $\mathrm{K}_{\mathrm{a}} \mathrm{K}_{\mathrm{s}}$ Calculator [30]. Positive selections in Dipterocarpoideae were tested based on a species tree we built. PRANK v170427 [31] was used to perform multiple alignments for the protein-coding DNA sequences within each single gene. The alignments of each dataset were then fed into the Codeml program in the PAML package [32] to identify positively selected genes. Chi-square test $\mathrm{p}$ value $<0.05$ is positive.

\section{Phylogenetic inference}

We downloaded 12 published chloroplast genome sequences (three as the outgroup taxa) from Genbank that were included in the analyses to perform the phylogenetic reconstruction. Firstly, all single-copy genes were extracted from 23 taxa, and alignments of each gene were generated and trimmed. Secondly, these alignments were concatenated which were used for phylogenetic analysis. Finally, phylogenetic trees were constructed using Bayesian analysis (BI) methods with MrBayes v3.2.2 [33], Maximum likelihood (ML) method with PhyML v3.0 [34] and Neighbour-joining (NJ) method with TreeBeST v1.9.2 [35]. The supporting branches were assessed with 100 rapid bootstrapping replicates.

\section{p-distance calculation}

To screen for rapidly evolving regions of some marker genes, we aligned the target genes by MUSCLE [36] after the annotation of $20 \mathrm{cp}$ genomes of Dipterocarpoideae species. The FASTA format file was then transformed into mega format by MEGA7 [37]. Estimation of sequence divergence was expressed as the $p$-distance quantification using the Kimura 2-parameter model [38].

\section{Results}

Comparison among chloroplast genomic features in Dipterocarpoideae

The chloroplast genome size of $V$. xishuangbannaensis (151,011 bp) was found to be the smallest and S. leprosula $(152,100 \mathrm{bp})$ was found to be the largest (Fig. 1, Additional file 1: Fig. S1). The lengths of LSC, SSC, and IR of the 11 species are also shown in Table 1. In these species we found 110-111 unique genes including 78-79 protein coding genes, four rRNA genes, and 28 tRNA genes (Tables 1, 2).

The mVISTA program was further used to align the cp genomes and visualize the pattern of sequence identity along the whole chloroplast genome of the 23 species including 20 Dipterocarpoideae species and three outgroups, using the annotation for $H$. mollissima as a reference (Fig. 2). Compared with the three outgroups, all 20 chloroplast genomes Dipterocarpoideae species displayed similar structure and gene order. The coding regions were more conserved than non-coding regions in all the species tested. In addition, LSC and SSC regions had a larger divergence than the IR regions, which has been observed in $\mathrm{cP}$ genome study of other taxa [39, 40]. In total, all 20 Dipterocarpoideae species showed conserved gene and gene organization.

The overall guanine-cytosine (GC) content was also very conserved, ranged only from $37.1 \%$ (P. chinensis) to $37.5 \%$ ( $H$. dryobalanoides) in Dipterocarpoideae. GC content in the LSC, SSC and IR regions was 35.2$35.3 \%, 31.3-31.9 \%$ and $43.0-43.2 \%$, respectively. IR regions showed high GC content compared to the LSC and SSC regions (Table 1; Fig. 3).

\section{Contraction and expansion of inverted repeats}

The contraction and expansion of IR regions are the main contributors to the size variation in cp genomes and alter the evolutionary rate of the cp genome [41, 42]. We compared the IR boundaries in 20 Dipterocarpoideae species and found that the IR boundary regions varied slightly, especially IRb/SSC, SSC/IRa, and IRa/LSC (Fig. 4). At the junction of LSC and IRb regions, the rps 19 gene was found completely covered by the LSC region in most species but extended into IRb region in only four Dipterocarpus species and H.hainanensis, while $r p l 2$ was present completely in the IR regions. The analysis of the IRb/SSC junction showed the complete presence of $y c f 1$ in the SSC region. The $n d h F$ was found at the junction of IRa/ SSC. The size of $n d h F$ in IRa was ranged from 43 to $73 \mathrm{bp}$. The IR boundary characteristics of all other species were conserved, the contraction and expansion were not obvious in Dipterocarpoideae. 


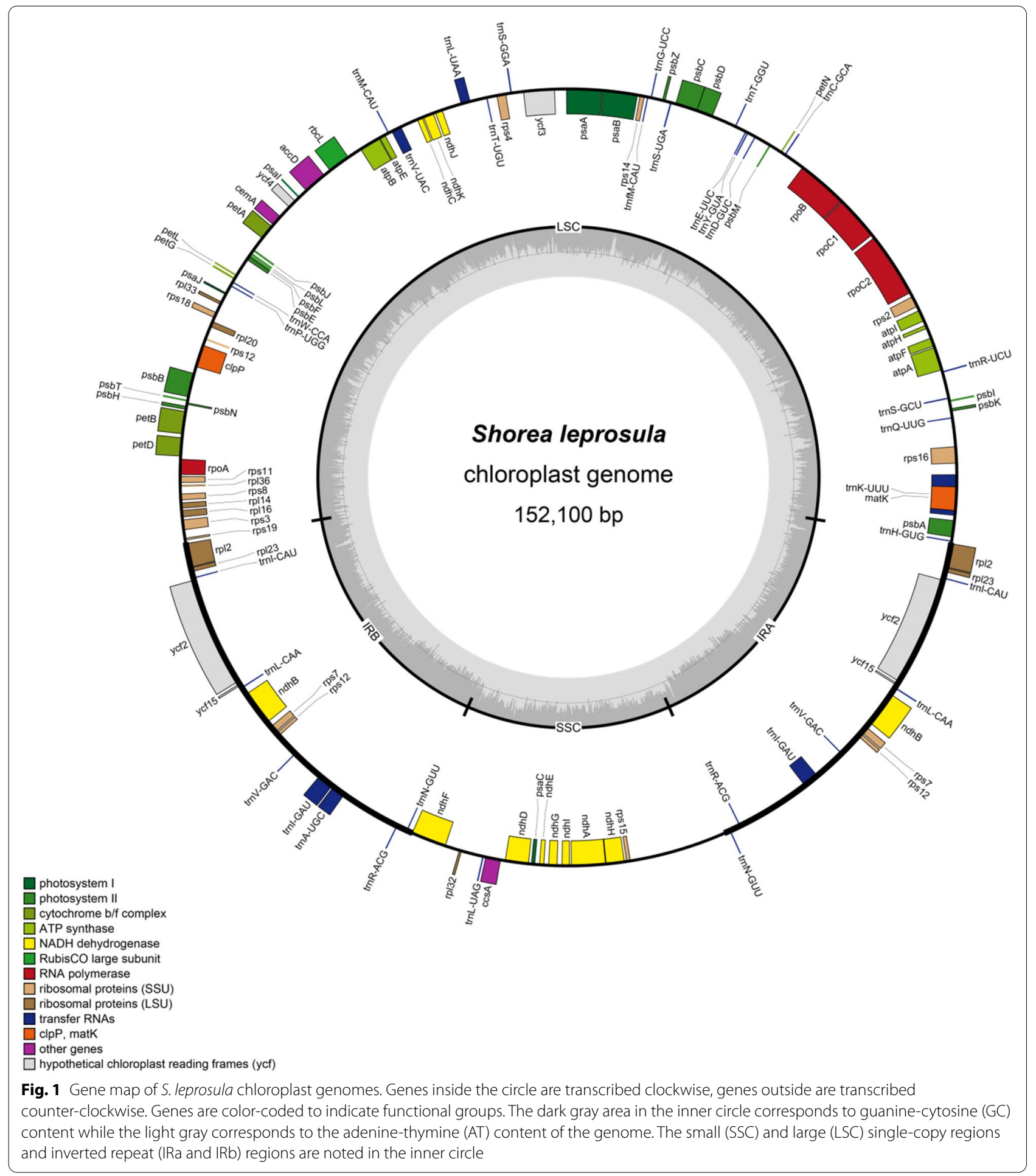

\section{Codon usage and amino acid frequency}

To characterize the evolution of the codon usage in the Dipterocarpoideae species, we measured the codon usage bias of all protein-coding genes in cp genome of the eleven species (Tables 3 and 4, Additional file 2: Table S1). We calculated the codon usage bias through the relative synonymous codon usage (RSCU). In addition to the normal ATG start codon that encodes 
Table 1 Characteristics of the chloroplast genomes of eleven Dipterocarpoideae species

\begin{tabular}{|c|c|c|c|c|c|c|c|c|}
\hline \multirow[t]{2}{*}{ Taxon } & \multirow[t]{2}{*}{ Size (bp) } & \multirow[t]{2}{*}{ LSC length (bp) } & \multirow[t]{2}{*}{ SSC length (bp) } & \multirow[t]{2}{*}{ IR length (bp) } & \multicolumn{4}{|c|}{ GC conten $\mathrm{t}(\%)$} \\
\hline & & & & & Total & LSC & SSC & IR \\
\hline D.gracilis & 152,015 & 83,302 & 20,237 & 24,238 & 37.2 & 35.2 & 31.5 & 43.0 \\
\hline D. alatus & 151,638 & 83,101 & 20,199 & 24,169 & 37.3 & 35.3 & 31.7 & 43.0 \\
\hline D. intricatus & 151,911 & 83,169 & 20,310 & 24,216 & 37.2 & 35.2 & 31.5 & 43.0 \\
\hline H. mollissima & 151,497 & 84,281 & 19,702 & 23,757 & 37.4 & 35.3 & 31.9 & 43.3 \\
\hline H. odorata & 151,745 & 84,529 & 19,678 & 23,769 & 37.3 & 35.3 & 31.9 & 43.3 \\
\hline S. leprosula & 152,100 & 84,226 & 19,940 & 23,967 & 37.2 & 35.2 & 31.6 & 43.1 \\
\hline S. roxburghii & 151,795 & 84,406 & 19,833 & 23,778 & 37.2 & 35.2 & 31.6 & 43.2 \\
\hline S. henryana & 151,685 & 84,144 & 19,865 & 23,838 & 37.4 & 35.3 & 31.8 & 43.2 \\
\hline V.xishuangbannaensis & 151,011 & 83,210 & 20,029 & 23,886 & 37.2 & 35.2 & 31.3 & 43.2 \\
\hline V. odorata & 151,493 & 83,532 & 20,067 & 23,947 & 37.2 & 35.2 & 31.3 & 43.1 \\
\hline V.rassak & 151,394 & 83,380 & 20,204 & 23,905 & 37.2 & 35.2 & 31.3 & 43.1 \\
\hline
\end{tabular}

Table 2 Genes difference of the chloroplast genomes of eleven Dipterocarpoideae species

\begin{tabular}{|c|c|c|c|c|c|c|}
\hline \multirow[t]{2}{*}{ Taxon } & \multirow[t]{2}{*}{ Number of genes } & \multirow[t]{2}{*}{$\begin{array}{l}\text { Protein-coding } \\
\text { genes }\end{array}$} & \multirow[t]{2}{*}{ rRNA genes } & \multirow[t]{2}{*}{ tRNA genes } & \multicolumn{2}{|c|}{$\begin{array}{l}\text { Genes content } \\
\text { difference }\end{array}$} \\
\hline & & & & & rps16 & ycf15 \\
\hline D.gracilis & 110 & 78 & 4 & 28 & $N$ & Y \\
\hline D. alatus & 110 & 78 & 4 & 28 & $N$ & Y \\
\hline D. intricatus & 110 & 78 & 4 & 28 & $\mathrm{~N}$ & Y \\
\hline H. mollissima & 111 & 79 & 4 & 28 & Y & Y \\
\hline H. odorata & 111 & 79 & 4 & 28 & Y & Y \\
\hline S. leprosula & 111 & 79 & 4 & 28 & Y & Y \\
\hline S. roxburghii & 111 & 79 & 4 & 28 & Y & Y \\
\hline S. henryana & 110 & 78 & 4 & 28 & Y & N \\
\hline V.xishuangbannaensis & 110 & 78 & 4 & 28 & Y & N \\
\hline V. odorata & 111 & 79 & 4 & 28 & Y & Y \\
\hline V.rassak & 111 & 79 & 4 & 28 & Y & Y \\
\hline
\end{tabular}

$Y$ The gene exists in this species; $N$ The gene does not exist in this species

formyl-methionine, alternative start codons have also been found in Araceae species, including ACG, ATA, and GTG [43]. However, in our research, start codon was only ATG with no amino acid bias. While the arginine (Arg), leucine (Leu) and serine (Ser) were encoded by six codons with the highest preferences. Especially, the maximum (1.73-1.98) and minimum (0.43-0.51) values of RSCU were found in Arg (except $H$. odorata). In addition, the $\mathrm{G} / \mathrm{C}$ at $3^{\prime}$ end content values were $32.5 \%$ in $H$. odorata to $37.8 \%$ in $V$. odorata, which indicates that these genes preferred the codons ended with $\mathrm{A} / \mathrm{U}$. Other indicators that related to RSCU are relatively conserved among species, including the codon adaptation index (CAI), the codon usage index (CBI), frequency of optimal codons (Fop), the effective number of codons (ENc) and GC content of synonymous third codons positions (GC3s) .

\section{Repeat analyses}

We used two methods (TandemRepeatFinder and RepeatMasker) to analyze the repetitive sequence in eleven Dipterocarpoideae cp genomes (Fig. 5). The results showed that there were slightly more tandem repeats in cp genomes of Dipterocarpoideae, while the cp genomes of Hopea and Shorea retained slightly more transposable factors (TE) than the tandem repeats. The numbers of four types TEs repeats in the eleven Dipterocarpoideae cp genomes were similar and conserved (Table 5) LTR (long terminal repeats) 


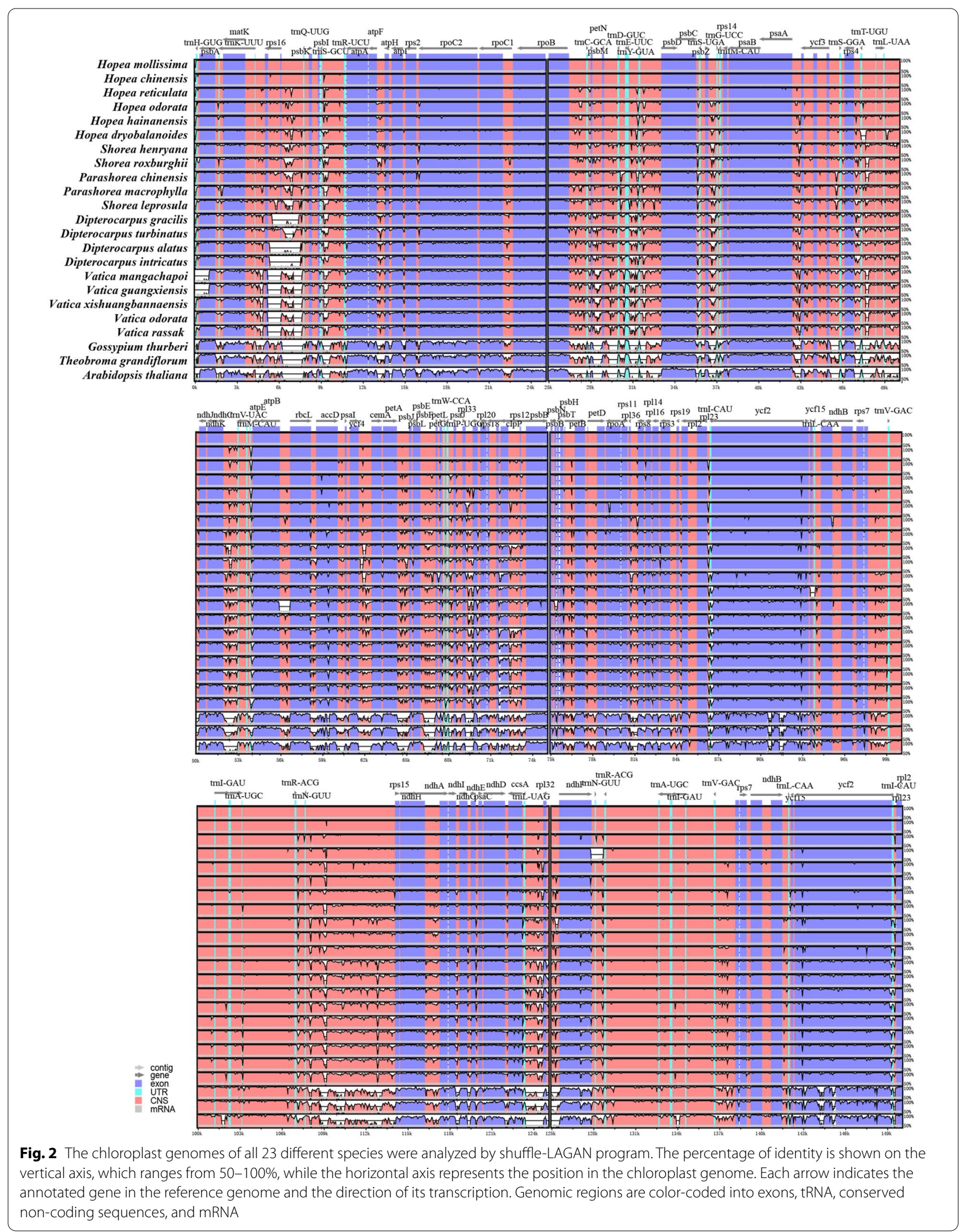




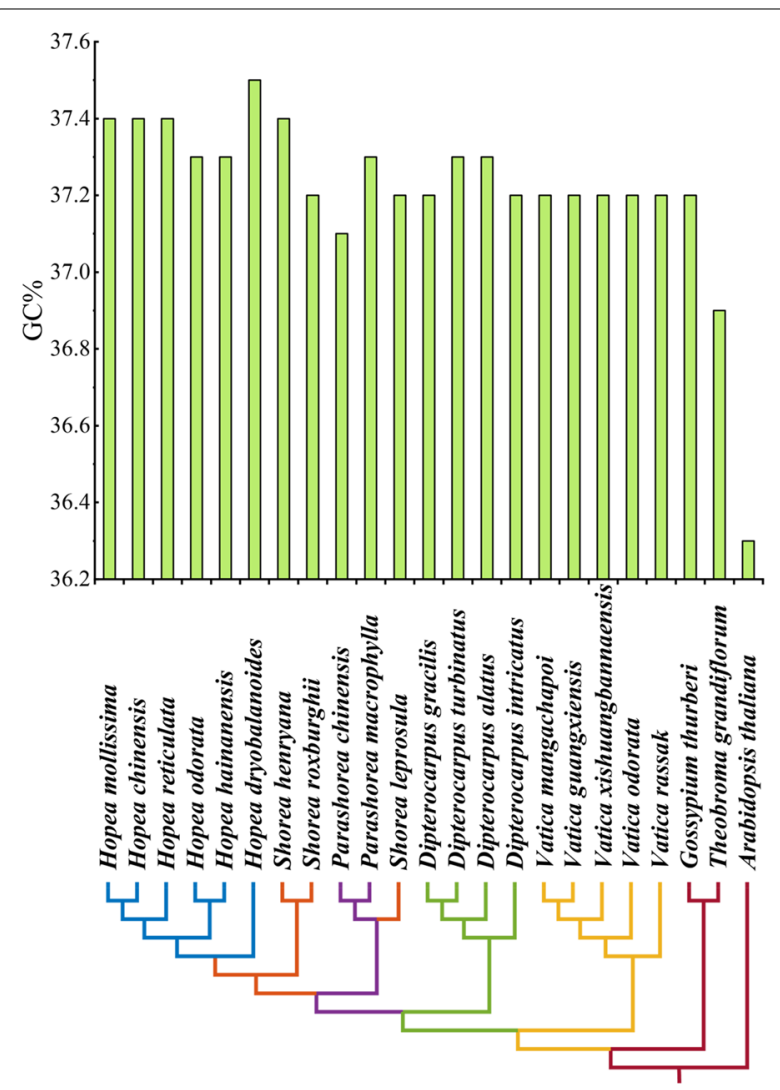

Fig. 3 Changes in chloroplast GC content of all 23 species

was the most abundant TE followed by DNA and LINE (long interspersed nuclear elements).

\section{Selective pressure analysis}

The pairwise $K_{a} / K_{s}$ ratios of all 23 species pair were calculated using the concatenated 50 single-copy genes alignments (Fig. 6). The ratios among species of Dipterocarpaceae were much higher than those involving the outgroups. The $\mathrm{K}_{\mathrm{a}} / \mathrm{K}_{\mathrm{s}}$ ratios of $D$. gracilis-D. intricatus pair and D. gracilis-D. turbinatus pair were detected highes. The elevated $\mathrm{K}_{\mathrm{a}} / \mathrm{K}_{\mathrm{s}}$ ratios are unlikely to be explained by changes in codon preference since we did not obtain obvious codon usage bias in Dipterocarpoideae species (Additional file 2: Table S1). So we consider that it may be an indication of an elevated mutation rate that caused the $\mathrm{K}_{\mathrm{a}} /$ $\mathrm{K}_{\mathrm{s}}$ ratios exceptionally high. We observed similar phenomenon in other research and they also inferred that high $\mathrm{K}_{\mathrm{a}} / \mathrm{K}_{\mathrm{s}}$ ratios was caused by elevated mutation rate [44].

Since the short episodes of positive selection signal at of some sites may be masked by the long-term history of purification selection in the paired $\mathrm{K}_{\mathrm{a}}$ l $\mathrm{K}_{\mathrm{s}}$ test, we carried out positive selection test using the branch-site model implemented in PAML. The results showed that five genes ( $p s b M, r b c L, r p s 7, r p s 2$, $p s b H)$ have been positively selected $(p<0.05)$ at four branches (Figs. 7 and 8; Table 6). Among them, four genes had more than one positively selected site. The $p s b H$ gene at branch III which was ancestor of 20 Dipterocarpoideae species, with four positively selected sites, rps 2 gene at branch IV possessed three sites under positive selection, followed by $r p s 7$ and $r b c L$ at branch II and I had two positively selected sites, $p s b M$ gene at branch I possessed one positively selected site. The $p s b H$ gene was subjected to positive selection in the common ancestor of all the 20 species of Dipterocarpoideae (T5S, A48G, I57L, S71R) compared with three outgroups. And when we observed the alignment matrix of PSBM encoded by $p s b M$, we found that the sixth amino acid was Alanine (A) in all Hopea species, but was Leucine (L) or Valine $(\mathrm{V})$ in other species. In addition, the six Hopea species (H. mollissima, $H$. chinensis, $H$. reticulata, $H$. odorata, $H$. hainanensis, $H$. dryobalanoides) have specific mutations at two positions in $r b c L$ gene (I375L, A398S).

\section{Phylogenetic relationships among Dipterocarpoideae}

A total of 20 Dipterocarpoideae cp genomes were used to perform phylogenetic analysis. Gossypium thurberi, Theobroma grandiflorum and Arabidopsis thaliana were used as the outgroups. The phylogenetic tree was constructed using Bayesian analysis (BI), ML and NJ methods based on 50 single-copy genes (Fig. 7). All phylogenetic trees have the same topology. The bootstrap values of almost nodes were equal to 100. Each genus clustered together to form a single clade except Shorea in which most species clustered together while Shorea leprosula clustered with the Parashorea species which has been reported by Jacqueline Heckenhauer et al. [45].

\section{Analysis of chloroplast barcoding loci}

DNA barcoding is currently an effective and widely used tool that enables rapid and accurate identification of plant species. We found a number of potential marker genes (accD, matK, rbcL, rpoA, rpoB, rpoC1, rpoC2, ycf1 and $n d h F)[46,47]$ that may be used in identification of Dipterocarpoideae. Then, two criteria were satisfied for an ideal candidate DNA barcoding locus: (i) Sequences in all 20 species are divergent (ii) The phylogenetic trees based on the marker gene through the ML method with the same parameters are almost the same as the tree based on single-copy genes $[46,48]$. The average $p$-distance values between 20 species of rpoC2 were 0.014-0.021 (Additional file 3: Table S2) which were larger than the average 


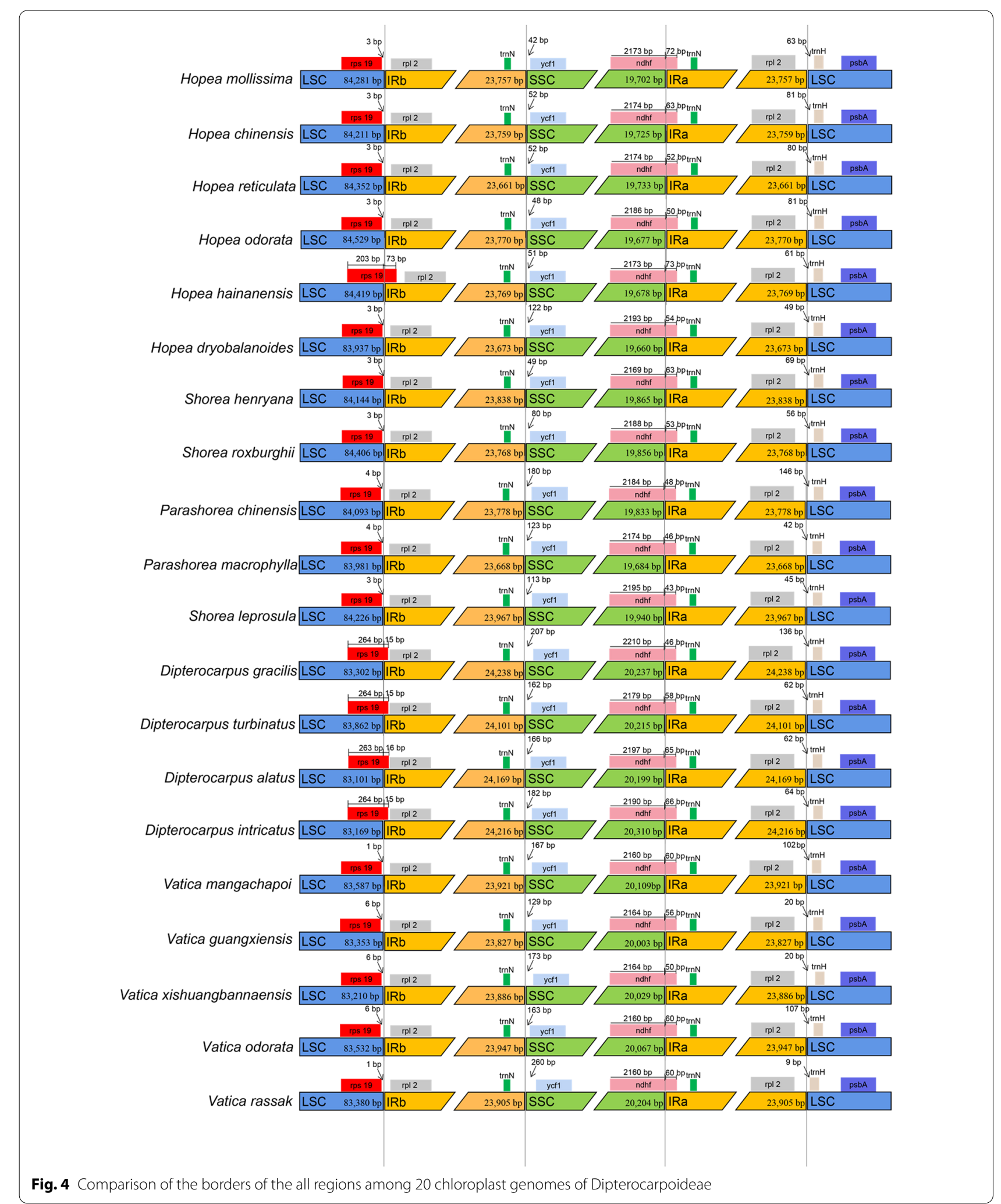


Table 3 The indexes of the codon usage bias of protein-coding genes of Dipterocarpoideae

\begin{tabular}{llllll}
\hline & CAI & CBI & Fop & ENc & GC3s \\
\hline D.gracilis & 0.164 & -0.079 & 0.369 & 55.47 & 0.359 \\
D. alatus & 0.155 & -0.082 & 0.366 & 57.93 & 0.413 \\
D.intricatus & 0.158 & -0.105 & 0.363 & 55.08 & 0.369 \\
H.mollissima & 0.162 & -0.078 & 0.365 & 56.08 & 0.366 \\
H.odorata & 0.169 & -0.082 & 0.369 & 53.64 & 0.329 \\
S.leprosula & 0.168 & -0.087 & 0.365 & 53.99 & 0.332 \\
S.roxburghii & 0.166 & -0.085 & 0.366 & 54.1 & 0.335 \\
S.henryana & 0.161 & -0.079 & 0.364 & 56.05 & 0.365 \\
V.xishuangbannaensis & 0.157 & -0.082 & 0.364 & 57.19 & 0.394 \\
V.odorata & 0.158 & -0.096 & 0.362 & 56.41 & 0.378 \\
V. rassak & 0.163 & -0.088 & 0.366 & 56.22 & 0.376 \\
\hline
\end{tabular}

value in protein-coding genes of Magnoliaceae [49]. After filtering with these two criteria, only the rpoC2 gene was left, suggestiong that rpoC2 was a potential cp barcoding locus of Dipterocarpoideae (Additional file 3: Table S2).

\section{Discussion}

Our comparison of cp genome structure and content of all the $20 \mathrm{cp}$ genomes in the same family showed that the gene content and genome organization are conserved across species in this family. There were some differences of rps 16 and $y c f 15$ among the species. In our eleven cp genomes, only three species lack rps16 (D. gracilis, D. alatus and D. intricatus) and $y c f 15$ is absent in two species (S. henryana and $V$.

Table 4 Codon content of 20 amino acids and stop codons in H.odorata

\begin{tabular}{|c|c|c|c|c|c|c|c|}
\hline \multicolumn{8}{|c|}{ H. odorata } \\
\hline $\mathrm{AA}$ & Codons & Numbers & RSCU & $A A$ & Codons & Numbers & $\mathrm{RSCU}$ \\
\hline \multirow[t]{2}{*}{ Phe } & UUU & 1187 & 1.25 & Ser & UCU & 787 & 1.63 \\
\hline & UUC & 707 & 0.75 & & UCC & 486 & 1.01 \\
\hline \multirow[t]{6}{*}{ Leu } & UUA & 763 & 1.61 & & UCA & 545 & 1.13 \\
\hline & UUG & 606 & 1.28 & & UCG & 307 & 0.64 \\
\hline & CUU & 635 & 1.34 & Pro & CCU & 445 & 1.32 \\
\hline & CUC & 255 & 0.54 & & $\mathrm{CCC}$ & 302 & 0.9 \\
\hline & CUA & 365 & 0.77 & & CCA & 377 & 1.12 \\
\hline & CUG & 226 & 0.48 & & CCG & 225 & 0.67 \\
\hline \multirow[t]{3}{*}{ Ile } & AUU & 1126 & 1.44 & Thr & ACU & 510 & 1.33 \\
\hline & $A \cup C$ & 618 & 0.79 & & ACC & 348 & 0.91 \\
\hline & AUA & 605 & 0.77 & & ACA & 441 & 1.15 \\
\hline Met & AUG & 593 & 1 & & ACG & 236 & 0.61 \\
\hline \multirow[t]{4}{*}{ Val } & GUU & 571 & 1.44 & Ala & $\mathrm{GCU}$ & 606 & 1.61 \\
\hline & GUC & 235 & 0.59 & & GCC & 264 & 0.7 \\
\hline & GUA & 520 & 1.31 & & GCA & 390 & 1.04 \\
\hline & GUG & 259 & 0.65 & & GCG & 246 & 0.65 \\
\hline \multirow[t]{2}{*}{ Tyr } & UAU & 879 & 1.44 & Cys & UGU & 329 & 1.17 \\
\hline & UAC & 338 & 0.56 & & UGC & 233 & 0.83 \\
\hline \multirow[t]{2}{*}{ TER } & UAA & 292 & 0.94 & TER & UGA & 410 & 1.32 \\
\hline & UAG & 228 & 0.74 & $\operatorname{Trp}$ & UGG & 550 & 1 \\
\hline \multirow[t]{2}{*}{ His } & CAU & 567 & 1.46 & Arg & CGU & 365 & 0.97 \\
\hline & CAC & 211 & 0.54 & & CGC & 180 & 0.48 \\
\hline \multirow[t]{2}{*}{ Gln } & CAA & 772 & 1.47 & & CGA & 472 & 1.26 \\
\hline & CAG & 281 & 0.53 & & CGG & 208 & 0.55 \\
\hline \multirow[t]{2}{*}{ Asn } & AAU & 1006 & 1.42 & Ser & $A G U$ & 481 & 1 \\
\hline & AAC & 410 & 0.58 & & AGC & 286 & 0.59 \\
\hline \multirow[t]{2}{*}{ Lys } & AAA & 1081 & 1.4 & Arg & AGA & 686 & 1.83 \\
\hline & AAG & 458 & 0.6 & & AGG & 339 & 0.9 \\
\hline \multirow[t]{2}{*}{ Asp } & GAU & 875 & 1.53 & Gly & GGU & 603 & 1.13 \\
\hline & GAC & 267 & 0.47 & & GGC & 270 & 0.51 \\
\hline \multirow[t]{2}{*}{ Glu } & GAA & 1086 & 1.39 & & GGA & 802 & 1.5 \\
\hline & GAG & 480 & 0.61 & & GGG & 458 & 0.86 \\
\hline
\end{tabular}




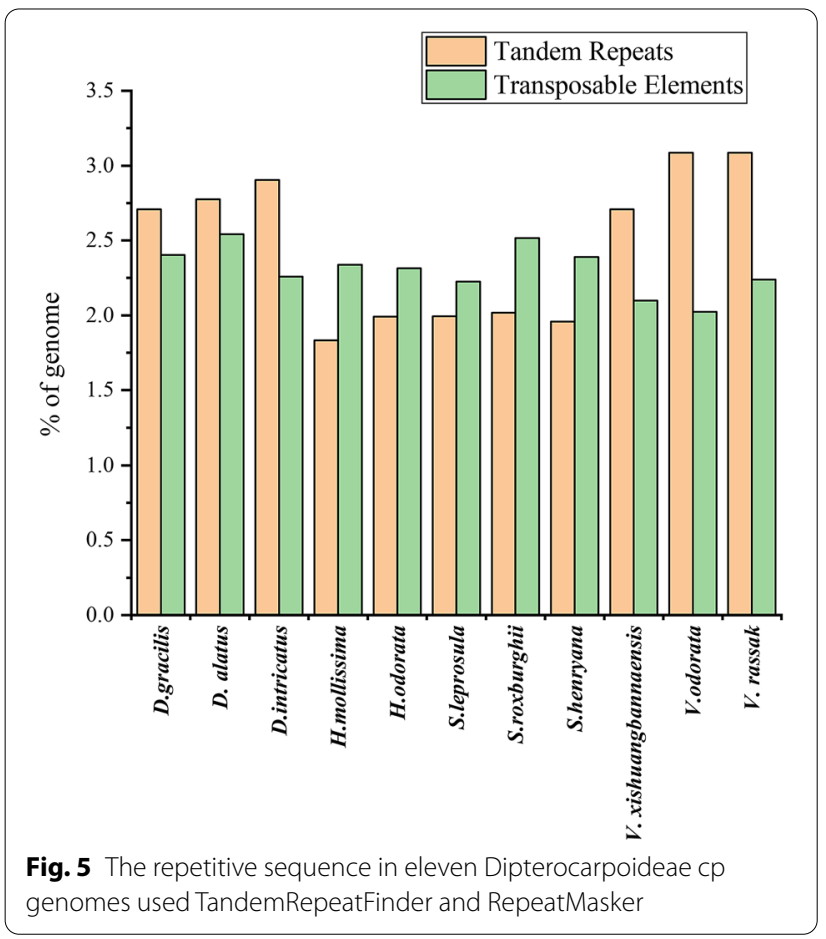

Table 5 Numbers of the TE repeat types in the eleven Dipterocarpoideae cp genomes

\begin{tabular}{lrrlll}
\hline Type length (bp) & DNA & LINE & SINE & LTR & Total \\
\hline D. gracilis & 1125 & 150 & 0 & 2597 & 3872 \\
D. alatus & 1122 & 150 & 0 & 2581 & 3853 \\
D. intricatus & 1106 & 50 & 0 & 2494 & 3650 \\
H. mollissima & 1021 & 228 & 0 & 2499 & 3748 \\
H. odorata & 1012 & 228 & 0 & 2479 & 3719 \\
S. leprosula & 1019 & 147 & 0 & 2426 & 3592 \\
S. roxburghii & 1197 & 147 & 0 & 2701 & 4045 \\
S. henryana & 1191 & 147 & 0 & 2630 & 3849 \\
V.xishuangbannaensis & 1017 & 90 & 0 & 2086 & 3170 \\
V. odorata & 912 & 51 & 0 & 2376 & 3316 \\
V. rassak & 1083 & 39 & 0 & 2268 & 3390
\end{tabular}

xishuangbannaensis). The absence and pseudogene of the two genes have been also reported in other species $[50,51]$.

Codon usage changes have important contribution to cp genome evolution [52], and our results showed that codon usage bias was conserved across species in Dipterocarpoideae. In addition, most codons preferentially ended with $\mathrm{A} / \mathrm{U}$ with $\mathrm{RSCU} \geq 1$, suggesting that certain degenerate codon usage bias was a result of the adaptive evolution of the cp genome [43]. Besides, all ENc values are larger than 53.64 and CAI, $\mathrm{CBI}$ and Fop value are much less than one, indicating that the codon usage biases in all the eleven species are very low.

PAML results showed low rates of evolution for all protein-coding genes in the chloroplast genomes. Five genes ( $p s b M, r b c L, r p s 7, r p s 2, p s b H)$ at four branches were under positive selection which might be due to different types of stresses faced by these species, and all the positively selected sites are in the known domains of the proteins (except the T5S and S71R sites of $p s b H)$. Three of the five genes, $p s b M, r b c L$ and $p s b H$, are involved in photosynthesis. Those three genes may function in the growth of all Dipterocarpoideae species in adaptation to a strongly illuminated environment [53].

The phylogenetic placement of Shorea is not clear. D. Gamage et al. [6] and S. Indrioko et al. [54] have built the phylogenetic tree used $\operatorname{trnL}$-trnF spacer, $\operatorname{trn} L$ intron, matK regions marker genes and $r b c L$, pet $B$, $p s b A$, psaA, and trnL-trnF regions marker genes, respectively, to build the phylogenetic tree, which showed that genus Shorea was not a monophyletic group. This result was not exactly consistent with the traditional taxonomy based on plant morphology. Our study generated a consistent phylogeny with high confidence on all nodes with three different phylogenetic algorithms. And we confirmed the result that Shorea was not monophyletic group, suggesting a new taxonomy treatment is needed for this genus.

Identification of specific plant species is helpful for the herbal medicine since the morphology of plants in the same subfamily are very similar. $D$. turbinatus has been proven with medicinal value (antibacterial, analgesic, anti-inflammatory effects and enhance anticancer efficiency) in Dipterocarpoideae analyzed in our study, so it has become necessary to develop easy and safe methods for the identification and development of Dipterocarpoideae species. In our study, rpoC2 was a potential barcoding gene which used to be a maker to achieve accurate and rapid species identification 


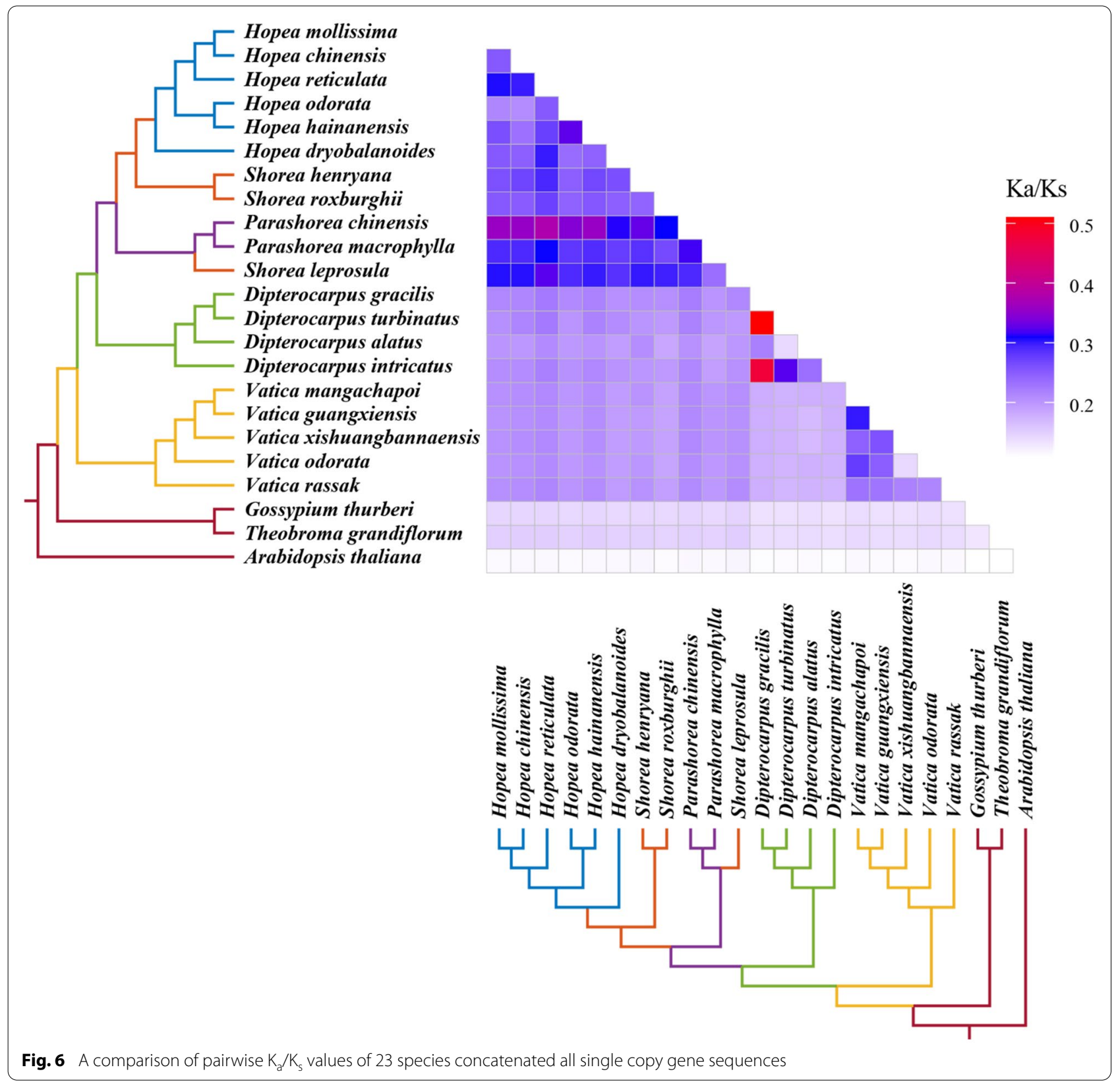

in subfamily Dipterocarpoideae with important traditional Chinese medicine value. However, experimental verification was needed to confirm the function of the barcoding gene further.

\section{Conclusions}

Eleven complete chloroplast genomes of Dipterocarpoideae were reported for the first time by us. Analysis of the cp genome sequences of 20 


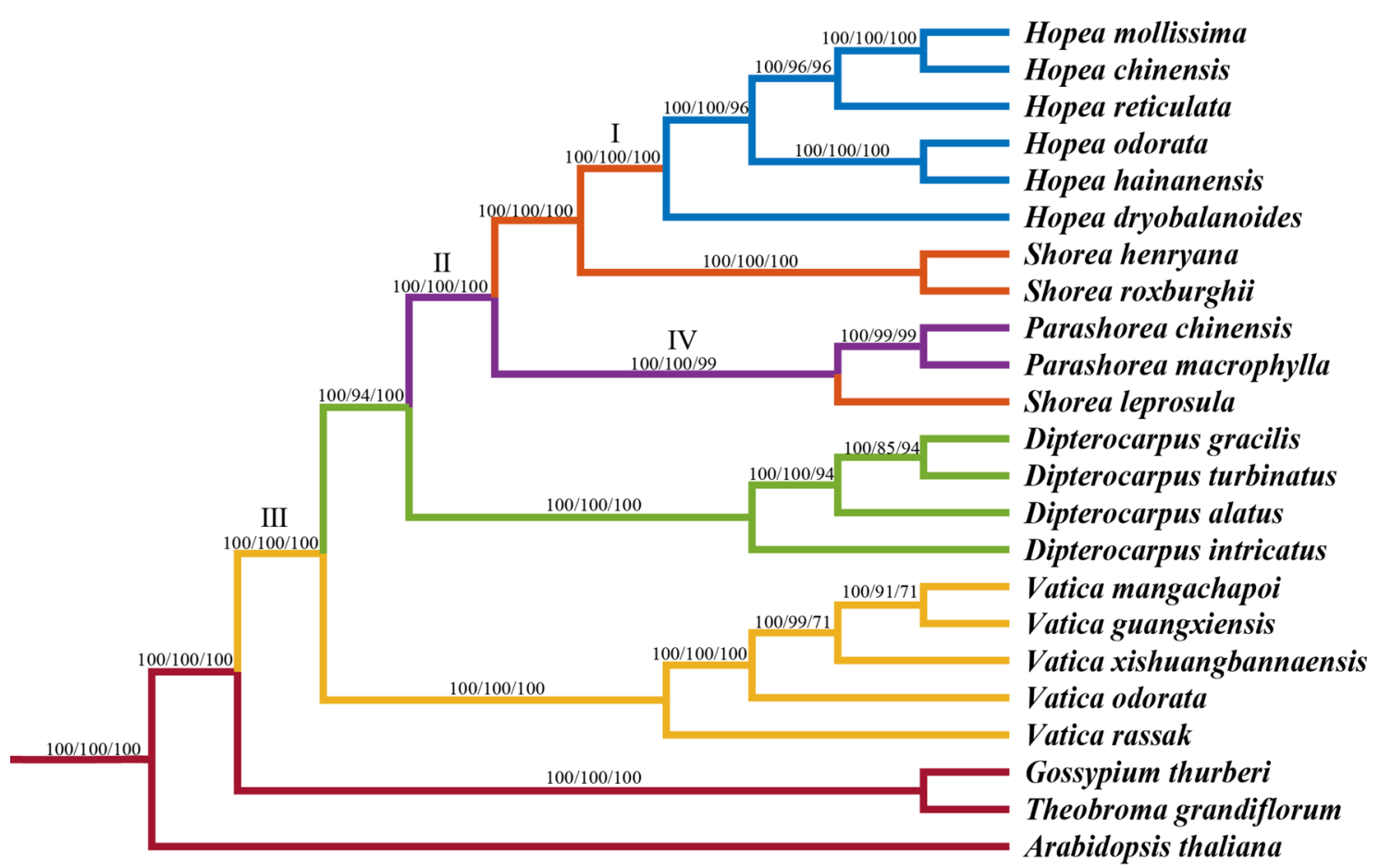

Fig. 7 Phylogenetic relationships of genus Dipterocarpoideae species with related species based on 50 single-copy genes. The topology is indicated with BI/ML/NJ bootstrap support values at each node. Roman scrip (I/II/III/IV) represent positively selected branches

Table 6 Test of positively selected sites in species based on branch-site model

\begin{tabular}{|c|c|c|c|}
\hline Genename & Branch & $p$-value & BEB \\
\hline psbM & I & 0.014 & 6:L:0.987* \\
\hline$r b c L$ & I & 0.047 & 375:L:0.765;398:S:0.655 \\
\hline rps7 & $\|$ & 0.011 & 43:I:0.684;85:H:0.839 \\
\hline psbH & III & 0.004 & $\begin{array}{l}\text { 5:T:0.807:48:A:0.752;57:I:0.754;7 } \\
\text { 1:S:0.974* }\end{array}$ \\
\hline rps2 & IV & 0.002 & 78:N:0.926;101:L:0.786;109:S:0.648 \\
\hline
\end{tabular}

* The sites with a posterior probability of positive selection over 0.95
Dipterocarpoideae species showed that they had very similar cp genomic structure, gene order, codon usage and repetitive sequence features. Positive selection analysis of the genes in chloroplast genome of this subfamily showed that $p s b H, p s b M$ and $r b c L$ may function in the growth of all Dipterocarpoideae species in adaptation to a strongly illuminated environment. Phylogenetic analysis based on all single-copy genes of chloroplast genome showed that genus Shorea was not a monophyletic group, suggesting a new taxon treatment is needed for this genus. In addition, we also recommended rpoC2 gene as a potential plant DNA barcoding locus to identify Dipterocarpoideae. 


\begin{tabular}{|c|c|c|c|c|c|c|c|c|c|}
\hline \multicolumn{2}{|l|}{ psbM } & \multicolumn{3}{|c|}{$r b c L$} & \multicolumn{4}{|c|}{ rps7 } & \multirow{2}{*}{$\mathrm{STR} \mathrm{R} Q \mathrm{Q}$} \\
\hline Hopea mollissima & N IÂA F & \multirow{2}{*}{\multicolumn{2}{|c|}{$\begin{array}{r}\text { Hopea mollissima } \\
\text { Hopea chinensis }\end{array}$}} & G VIIP V & DDAVL & \multirow{2}{*}{\multicolumn{2}{|c|}{$\begin{array}{c}\text { Hopea mollissima } \\
\text { Hopea chinensis }\end{array}$}} & QIIIY R & \\
\hline Hopea chinensis & NIAA $\mathrm{AF}$ & & & $\mathrm{G} \mathrm{VIP} \mathrm{V}$ & DDANL & & & QjLYR & \\
\hline Hopea reticulata & NIAA F & \multicolumn{2}{|c|}{ Hopea reticulata } & G V I P V & DDANL & \multicolumn{2}{|c|}{ Hopea reticulata } & QILYR & QV \\
\hline Hopea odorata & NIAAF & \multirow{2}{*}{\multicolumn{2}{|c|}{ Hopea odorata }} & $\mathrm{G} \mathrm{VIP} \mathrm{V}$ & DDANL & \multicolumn{2}{|c|}{ Hopea odorata } & QILYR & $2 \mathrm{QV}$ \\
\hline Hopea hainanensis & NIAA F & & & $\mathrm{G} \mathrm{VIP} \mathrm{V}$ & DDANL & \multicolumn{2}{|c|}{ Hopea hainanensis } & QILYR & $\mathrm{QV}$ \\
\hline Hopea dryobalanoides & NIA A F & \multicolumn{2}{|c|}{$\begin{array}{l}\text { Hopea hainanensis } \\
\text { opea dryobalanoides }\end{array}$} & $\mathrm{G} \mathrm{VIP} \mathrm{V}$ & DDAVL & \multirow{2}{*}{\multicolumn{2}{|c|}{$\begin{array}{r}\text { Hopea dryobalanoides } \\
\text { Shorea henryana }\end{array}$}} & QILYR & $2 \mathrm{QV}$ \\
\hline Shorea henryana & NILAF & \multicolumn{2}{|c|}{ Shorea henryana } & G VLP V & DDSVL & & & QILYR & S TRQV \\
\hline Shorea roxburghii & NIL A F & \multicolumn{2}{|c|}{ Shorea roxburghii } & G V L P V & DD S VL & \multicolumn{2}{|c|}{ Shorea roxburghii } & QILYR & S TRQV \\
\hline Parashorea chinensis & NIL A F & \multicolumn{2}{|c|}{ Parashorea chinensis } & GVLPV & DDSVL & \multicolumn{2}{|c|}{ Parashorea chinensis } & QILYR & STRQV \\
\hline Parashorea macrophylla & NIL A F & \multirow{2}{*}{\multicolumn{2}{|c|}{$\begin{array}{r}\text { Parashorea macrophylla } \\
\text { Shorea leprosula }\end{array}$}} & GV L P V & DD S V L & \multicolumn{2}{|c|}{ Parashorea macrophylla } & QHLYR & S TRQV \\
\hline Shorea leprosula & NIL A F & & & GVLPV & DDSVL & Shor & leprosula & QILYR & S TRQV \\
\hline Dipterocarpus gracilis & NILAF & Diptero & pus gracilis & GV L P V & DD S V L & Dipteroca & us gracilis & Q IIYR R & STHQV \\
\hline Dipterocarpus turbinatus & NILAF & Dipterocar & sturbinatus & G V L P V & DD S V L & Dipterocarpu & turbinatus & Q I I Y R & STHQV \\
\hline Dipterocarpus alatus & NILAF & Dipter & rpus alatus & GVLPV & DDSVL & Dipteroc & pus alatus & QIIYR & STHQV \\
\hline Dipterocarpus intricatus & NILAF & Dipteroca & Is intricatus & GVLPV & DD S V L & Dipterocarp & intricatus & Q I I Y R & STHQV \\
\hline Vatica mangachapoi & NIVAF & Vatica & angachapoi & GVLPV & DD S VL & Vatica $m$ & ngachapoi & QIIYR & STHQV \\
\hline Vatica guangxiensis & NIVAF & Vatice & uangxiensis & GVLPV & DD S V L & Vaticag & angxiensis & Q IIY R & STHQV \\
\hline Vatica xishuangbannaensis & NIVAF & Vatica xishuc & bannaensis & G V L P V & DD SVL & Vatica xishuan & annaensis & QIIY R & STHQV \\
\hline Vatica odorata & NIVAF & & fica odorata & GV L P V & DD S V L & & ca odorata & Q IIY R & STHQV \\
\hline Vatica rassak & NILAF & & atica rassak & G I L P V & DD S V L & & ica rassak & Q IIY R & STHQV \\
\hline Gossypium thurberi & NILAF & Goss] & Im thurberi & G V L P V & DD S V L & Gossypi & m thurberi & Q IIY R & STHQV \\
\hline Theobroma grandiflorum & NILAF & Theobrome & andiflorum & G V L P V & DD S VL & Theobroma $g$ & indiflorum & Q IIYR & STHQV \\
\hline Arabidopsis thaliana & NILAF & Arabic & sis thaliana & GV L P V & DDSVL & Arabido & is thaliana & QIIYR & STHQV \\
\hline rps2 & & & & & psbH & & & & \\
\hline Hopea mollissima & TK $\mathrm{K}^{78} \mathrm{KA}$ & $\begin{array}{c}101 \\
\text { KWLG }\end{array}$ & $\begin{array}{l}109 \\
\text { NWSNT }\end{array}$ & & Hopea mollissima & 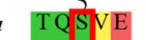 & $\mathrm{AM}$ & SIDLE & \\
\hline Hopea chinensis & T K N K A & KWLGG & NWSNT & & Hopea chinensis & TQSVE & AMGLF & SIL L E & $\mathrm{MN}$ \\
\hline Hopea reticulata & TKNKA & KWLGG & NWSNT & & Hopea reticulata & TQSVE & AMGLF & SILLE & $M N$ \\
\hline Hopea odorata & T K N K A & KWLGG & NWSNT & & Hopea odorata & TQSVE & AMGLF & $S I L L E$ & $\mathrm{MN}$ \\
\hline Hopea hainanensis & T K N K A & KWLGG & NWSNT & & Hopea hainanensis & TQSVE & AMGLF & SILLE & $\mathrm{MN}$ \\
\hline Hopea dryobalanoides & T K N K A & KWLGG & NWSNT & & opea dryobalanoides & TQSVE & AMGLF & SILLE & \\
\hline Shorea henryana & TKN K A & KWLGG & NWSTT & & Shorea henryana & TQSVE & AMGLF & SILLE & \\
\hline Shorea roxburghii & T K N K A & $\mathrm{KWLGG}$ & NWSTT & & Shorea roxburghii & TQSVE & AMGLF & SILLE & $R M N$ \\
\hline Parashorea chinensis & TTKK A & $\mathrm{K} \times \overline{\mathrm{I}} \mathrm{G}$ & NWAГT & & arashorea chinensis & TQSVE & AMGLF & SILLE & $\mathrm{MN}$ \\
\hline Parashorea macrophylla & $\mathrm{TKK} \mathrm{K} \mathrm{A}$ & $\mathrm{KWSGG}$ & NUATT & Para & ishorea macrophylla & TQSVE & $A M G L F$ & SILLE & $M N$ \\
\hline Shorea leprosula & $\mathrm{TKKKA}$ & $\mathrm{KWSGG}$ & NUATT & & Shorea leprosula & TQSVE & AMGLF & SILLE & $\mathrm{MN}$ \\
\hline Dipterocarpus gracilis & T K N K A & $\mathrm{K} W L \mathrm{LG}$ & NWSTT & & ipterocarpus gracilis & TQSVE & AMGLF & SILLE & $\mathrm{MN}$ \\
\hline Dipterocarpus turbinatus & T K N K A & $\mathrm{KWLGG}$ & NWSTT & Dipte & rocarpus turbinatus & TQSVE & AMGLF & SILLE & \\
\hline Dipterocarpus alatus & TK N K A & KWLGG & NWSTT & & Dipterocarpus alatus & TQSVE & AMGLF & SILLE & $\mathrm{MN}$ \\
\hline Dipterocarpus intricatus & TK K K A & KWLGG & NWSTT & Dipt & terocarpus intricatus & TQSVE & AMGLF & SILL E & \\
\hline Vatica mangachapoi & TKNKA & $\mathrm{K} W L \mathrm{LG}$ & NWSTT & & Vatica mangachapoi & TQSVE & AMGLF & SILLE & GIR MN \\
\hline Vatica guangxiensis & TKNK A & KWLGG & NWSTT & & Vatica guangxiensis & TQSVE & AMGLF & SILL E & GIRMN \\
\hline Vatica xishuangbannaensis & TKNKA & KWLGG & NWSTT & Vatica. & xishuangbannaensis & TQSVE & AMGLF & $S I L L E$ & \\
\hline Vatica odorata & TKNKA & KWLGG & NWSTT & & Vatica odorata & TQSVE & AMGLF & SILLE & GIRMN \\
\hline Vatica rassak & TKNKA & KWLGG & NWST I & & Vatica rassak & TQSVE & AMGLF & SILLE & GIRMN \\
\hline Gossypium thurberi & TKNKA & KWLGG & NWPTT & & Gossypium thurberi & TQTVE & AMALF & $\mathrm{S}$ I I L E & GISMN \\
\hline Theobroma grandiflorum & TKNKA & KWLGG & NWPTT & Theot & broma grandiflorum & TQTVE & AMALF & $\mathrm{S}$ I I L E & GIS MN \\
\hline Arabidopsis thaliana & TKNKA & KWLGG & NWSTT & & Arabidopsis thaliana & TQTVE & AMALF & SIILE & GISVN \\
\hline
\end{tabular}

\section{Abbreviations}

TCM: Traditional Chinese medicine; cp: Chloroplast; LSC: Large single copy; SSC: Small single copy; IR: Inverted repeat; rRNA: Ribosomal RNA; tRNA: Transfer RNA; LINE: Long interspersed nuclear elements; SINE: Short interspersed nuclear elements; LTR: Long terminal repeats; CAl: The codon adaptation index; CBI: Codon bias index; Fop: Frequency of optimal codons; ENC: The effective number of codons; GC3s: GC content of synonymous third codons positions; RSCU: The relative synonymous codon usage values; TEs: Transposable elements; BEB: Bayes Empirical Bayes.

\section{Supplementary Information}

The online version contains supplementary material available at https://doi. org/10.1186/s13020-021-00538-8.
Additional file 1: Figure S1. Gene map of the Dipterocarpoideae chloroplast genomes.

Additional file 2: Table S1. Codon content of 20 amino acids and stop codons in Dipterocarpoideae.

Additional file 3: Table S2. Estimates of Evolutionary Divergence between Sequences.

Acknowledgements

We thank Dr. Juan He from Northwestern Polytechnical University for her suggestions and modifications to the manuscript. We also thank Dr Yaowu Xing, Mr Yunxue Xiao and Mr Qiyong Mu from Xishuangbanna Tropical Botanical Garden, Chinese Academy of Sciences, for their help on collecting samples. 


\section{Authors' contributions}

CJ conceived the study and provided the funding, reviewed and revised the drafts of the paper. TZZ and ZP provided project ideas and overall process. YY analyzed data and wrote the manuscript, performed the genome assembly and annotation. ZH and ZTG analyzed the positive selection of all species. HYW and PYM analyzed data, completed the supplement of experimental data and review the final draft. All authors read and approved the final manuscript.

\section{Funding}

This work was supported by "the Thousand Talents Plan" to J.C. (5113190037); the Talents Team Construction Fund of Northwestern Polytechnical University (NWPU) (20GH020169); the Fundamental Research Funds for the Central Universities (3102019JC007).

\section{Availability of data and materials}

The datasets generated during the current study are available in the National Center for Biotechnology Information database (NCBI). www.ncbi.nlm.nih.gov/ [MZ160991-MZ160998, MZ379792, MZ397800-MZ397801].

\section{Declarations}

Ethics approval and consent to participate

Not applicable.

\section{Consent for publication}

Not applicable.

\section{Competing interests}

The authors declare that they have no competing interests.

\section{Author details}

${ }^{1}$ School of Ecology and Environment, Northwestern Polytechnical University, Xi'an, China. ${ }^{2}$ State Key Laboratory of Quality Research in Chinese Medicine, Institute of Chinese Medical Sciences, University of Macau, 999078 Macau, China.

Received: 12 September 2021 Accepted: 15 November 2021 Published online: 25 November 2021

\section{References}

1. Brearley FQ, Banin LF, Saner P. The ecology of the Asian dipterocarps. Plant Ecol Divers. 2017;9(5-6):429-36.

2. Ashton PS. Dipterocarpaceae. vol. 9; 1982.

3. Dwiyanti FG, Kamiya K, Harada K. Phylogeographic structure of the commercially important tropical tree species, Dryobalanops aromatica gaertn. f. (Dipterocarpaceae) revealed by microsatellite markers. Reinwardtia. 2014;14(1):43-51.

4. Slik JWF, Poulsen AD, Ashton PS, Cannon CH, Eichhorn KAO, Kartawinata K, Lanniari I, Nagamasu H, Nakagawa M, Van Nieuwstadt MGL, et al. A floristic analysis of the lowland dipterocarp forests of Borneo. J Biogeogr. 2003;30(10):1517-31.

5. Appanah S, Turnbull JM. A review of dipterocarps: Taxonomy, ecology, and silviculture. 1998

6. Gamage DT, De Silva MP, Inomata N, Yamazaki T, Szmidt AE. Comprehensive molecular phylogeny of the sub-family Dipterocarpoideae (Dipterocarpaceae) based on chloroplast DNA sequences. Genes Genetic Syst. 2006;81(1):1-12.

7. Schulte A. Dipterocarp forest ecosystems: towards sustainable management: World Scientific; 1996.

8. Ådjers G, Hadengganan S, Kuusipalo J, Nuryanto K, Vesa L. Enrichment planting of dipterocarps in logged-over secondary forests: effect of width, direction and maintenance method of planting line on selected Shorea species. For Ecol Manag. 1995;73(1-3):259-70.

9. Aswandi A, Kholibrina C. New insights into Sumatran camphor (Dryobalanops aromatica Gaertn) management and conservation in western coast Sumatra, Indonesia. In: IOP Conference Series: Earth and Environmental Science. 2021. IOP Publishing. p. 012061
10. Horváthová E, Slameňová D, Maršálková L, Šramková M, Wsólová L. Effects of borneol on the level of DNA damage induced in primary rat hepatocytes and testicular cells by hydrogen peroxide. Food Chem Toxicol. 2009;47(6):1318-23.

11. Yang L, Zhan C, Huang X, Hong L, Fang L, Wang W, Su J. Durable antibacterial cotton fabrics based on natural borneol-derived anti-MRSA agents. Adv Healthcare Mater. 2020;9(11):2000186.

12. Ji J, Zhang R, Li H, Zhu J, Pan Y, Guo Q. Analgesic and anti-inflammatory effects and mechanism of action of borneol on photodynamic therapy of acne. Environ Toxicol Pharmacol. 2020;75:103329.

13. Cao W-q, Li Y, Hou Y-j, Yang M-x, Fu X-q, Zhao B-s. Enhanced anticancer efficiency of doxorubicin against human glioma by natural borneol through triggering ROS-mediated signal. Biomed Pharmacother. 2019;118:109261.

14. Dong Z, Zhao Y, Chen J, Chang M, Wang X, Jin Q, Wang X. Enzymatic Lipophilization of $d$-Borneol Extracted from Cinnamomum camphora chvar. Borneol Seed. 2021;111:801.

15. van der Velden N, Slik JF, Hu Y-H, Lan G, Lin L, Deng X, Poorter L. Monodominance of Parashorea chinensis on fertile soils in a Chinese tropical rain forest. J Trop Ecol. 2014;232:311-22.

16. Li N, Su NC, Qiu BF, Zhong YD: Research on the Machining Properties of Parashorea chinensis Wood for Engineering. In: Advanced Materials Research: 2013. Trans Tech Publ: 78-82.

17. Cvetković T, Hinsinger DD, Strijk JS. Exploring evolution and diversity of Chinese Dipterocarpaceae using next-generation sequencing. Sci Rep. 2019;9(1):1-11.

18. Zhu X-F, Sun Y. The complete chloroplast genome of the endangered tree Parashorea chinensis (Dipterocarpaceae). Mitochondrial DNA Part B. 2019;4(1):1163-4.

19. Porebski S, Bailey LG, Baum BR. Modification of a CTAB DNA extraction protocol for plants containing high polysaccharide and polyphenol components. Plant Mol Biol Reporter. 1997;15(1):8-15.

20. Jin J-J, Yu W-B, Yang J-B, Song Y, dePamphilis CW, Yi T-S, Li D-Z. GetOrganelle: a fast and versatile toolkit for accurate de novo assembly of organelle genomes. Genome Biol. 2020;21(1):241.

21. Dierckxsens N, Mardulyn P, Smits G. NOVOPlasty: de novo assembly of organelle genomes from whole genome data. Nucleic Acids Res. 2016:45(4):e18-e18.

22. Hu J, Fan J, Sun Z, Liu S. NextPolish: a fast and efficient genome polishing tool for long-read assembly. Bioinformatics. 2019;36(7):2253-5.

23. Qu X-J, Moore MJ, Li D-Z, Yi T-S. PGA: a software package for rapid, accurate, and flexible batch annotation of plastomes. Plant Methods. 2019;15(1):50.

24. Laslett D, Canback B. ARAGORN, a program to detect tRNA genes and tmRNA genes in nucleotide sequences. Nucleic acids Res. 2004:32(1):11-6.

25. Lowe TM, Chan PP. tRNAscan-SE On-line: integrating search and context for analysis of transfer RNA genes. Nucleic Acids Res. 2016;44(W1):W54-7.

26. Greiner S, Lehwark P, Bock R. OrganellarGenomeDRAW (OGDRAW) version 1.3.1: expanded toolkit for the graphical visualization of organellar genomes. Nucleic Acids Res. 2019;47(W1):W59-64.

27. Benson G. Tandem repeats finder: a program to analyze DNA sequences. Nucleic Acids Res. 1999;27(2):573-80.

28. Brudno M, Malde S, Poliakov A, Do CB, Couronne O, Dubchak I, Batzoglou S. Glocal alignment: finding rearrangements during alignment. Bioinformatics. 2003;19(suppl_1):i54-62.

29. Lin D, Li L, Xie T, Yin Q, Saksena N, Wu R, Li W, Dai G, Ma J, Zhou X, et al. Codon usage variation of Zika virus: The potential roles of NS2B and NS4A in its global pandemic. Virus Res. 2018;247:71-83.

30. Wang D-P, Wan H-L, Zhang S, Yu J. Y-MYN: a new algorithm for estimating $\mathrm{Ka}$ and Ks with consideration of variable substitution rates. Biol Direct. 2009;4(1):1-18.

31. Löytynoja A. Phylogeny-aware alignment with PRANK. In: Multiple sequence alignment methods. Springer; 2014. p. 155-70.

32. Yang Z. PAML: a program package for phylogenetic analysis by maximum likelihood. Bioinformatics. 1997;13(5):555-6.

33. Ronquist F, Teslenko M, Van Der Mark P, Ayres DL, Darling A, Höhna S, Larget B, Liu L, Suchard MA, Huelsenbeck JP. MrBayes 3.2: efficient Bayesian phylogenetic inference and model choice across a large model space. System Biol. 2012;61(3):539-42. 
34. Guindon S, Gascuel O. A simple, fast, and accurate algorithm to estimate large phylogenies by maximum likelihood. System Biol. 2003;52(5):696-704.

35. Saitou N, Nei M. The neighbor-joining method: a new method for reconstructing phylogenetic trees. Mol Biol Evol. 1987;4(4):406-25.

36. Edgar RC. MUSCLE: multiple sequence alignment with high accuracy and high throughput. Nucleic Acids Res. 2004;32(5):1792-7.

37. Kumar S, Stecher G, Tamura K. MEGA7: molecular evolutionary genetics analysis version 7.0 for bigger datasets. Molecular biology and evolution. 2016;33(7):1870-4.

38. Srivathsan A, Meier R. On the inappropriate use of Kimura-2-parameter (K2P) divergences in the DNA-barcoding literature. Cladistics. 2012;28(2):190-4.

39. Huang R, Xie X, Li F, Tian E, Chao Z. Chloroplast genomes of two Mediterranean Bupleurum species and the phylogenetic relationship inferred from combined analysis with East Asian species. Planta. 2021;253(4):1-17.

40. Wu Z, Liao R, Yang T, Dong X, Lan D, Qin R, Liu H. Analysis of six chloroplast genomes provides insight into the evolution of Chrysosplenium (Saxifragaceae). BMC Genomics. 2020;21(1):1-14.

41. Zhang H, Li C, Miao H, Xiong S: Insights from the complete chloroplast genome into the evolution of Sesamum indicum L. PloS one 2013, 8(11):e80508.

42. Choi KS, Ha Y-H, Gil H-Y, Choi K, Kim D-K, Oh S-H. Two Korean endemic Clematis chloroplast genomes: Inversion, reposition, expansion of the inverted repeat region, phylogenetic analysis, and nucleotide substitution rates. Plants. 2021;10(2):397.

43. Henriquez CL, Ahmed I, Carlsen MM, Zuluaga A, Croat TB, McKain MR. Molecular evolution of chloroplast genomes in Monsteroideae (Araceae). Planta. 2020;251(3):1-16.

44. Xie D-F, Yu H-X, Price M, Xie C, Deng Y-Q, Chen J-P, Yu Y, Zhou S-D, He X-J. Phylogeny of Chinese Allium species in section Daghestanica and adaptive evolution of Allium (Amaryllidaceae, Allioideae) species revealed by the chloroplast complete genome. Front Plant Sci. 2019;10:460.

45. Heckenhauer J, Samuel R, Ashton PS, Turner B, Barfuss MH, Jang T-S, Temsch EM, Mccann J, Salim KA, Attanayake A. Phylogenetic analyses of plastid DNA suggest a different interpretation of morphological evolution than those used as the basis for previous classifications of Dipterocarpaceae (Malvales). Bot J Linnean Soc. 2017;185(1):1-26.

46. Krawczyk K, Szczecińska M, Sawicki J. Evaluation of 11 single-locus and seven multilocus DNA barcodes in L amium L.(L amiaceae). Mol Ecol Resour. 2014;14(2):272-85.

47. Li H, Xiao W, Tong T, Li Y, Zhang M, Lin X, Zou X, Wu Q, Guo X. The specific DNA barcodes based on chloroplast genes for species identification of Orchidaceae plants. Scientific Reports. 2021;11(1):1-15.

48. Moon J-C, Kim J-H, Jang CS. Development of multiplex PCR for speciesspecific identification of the Poaceae family based on chloroplast gene, rpoC2. Appl Biol Chem. 2016;59(2):201-7.

49. Kuang D-Y, Wu H, Wang Y-L, Gao L-M, Zhang S-Z, Lu L. Complete chloroplast genome sequence of Magnolia kwangsiensis (Magnoliaceae): implication for DNA barcoding and population genetics. Genome. 2011;54(8):663-73.

50. Steele PR, Hertweck KL, Mayfield D, McKain MR, Leebens-Mack J, Pires JC. Quality and quantity of data recovered from massively parallel sequencing: examples in Asparagales and Poaceae. Am J Bot. 2012;99(2):330-48.

51. Huo Y, Gao L, Liu B, Yang Y, Kong S, Sun Y, Yang Y, Wu X. Complete chloroplast genome sequences of four Allium species: comparative and phylogenetic analyses. Scientific reports. 2019;9(1):1-14.

52. Yan C, Du J, Gao L, Li Y, Hou X. The complete chloroplast genome sequence of watercress (Nasturtium officinale RBr): Genome organization, adaptive evolution and phylogenetic relationships in Cardamineae. Gene. 2019;699:24-36.

53. Brearley FQ, Banin LF, Saner P. The ecology of the Asian dipterocarps. Plant Ecology \& Diversity. 2016;9(5-6):429-36.

54. Indrioko S, Gailing O, Finkeldey R. Molecular phylogeny of Dipterocarpaceae in Indonesia based on chloroplast DNA. Plant Systematics and Evolution. 2006;261(1):99-115.

\section{Publisher's Note}

Springer Nature remains neutral with regard to jurisdictional claims in published maps and institutional affiliations.
Ready to submit your research? Choose BMC and benefit from:

- fast, convenient online submission

- thorough peer review by experienced researchers in your field

- rapid publication on acceptance

- support for research data, including large and complex data types

- gold Open Access which fosters wider collaboration and increased citations

- maximum visibility for your research: over $100 \mathrm{M}$ website views per year

At BMC, research is always in progress.

Learn more biomedcentral.com/submissions 